\title{
The Ethical Cerebration of City Spirit
}

\author{
Ning Yang \\ Party Committee Office, Guangxi Open University, Nanning, China
}

Feng Qin

Department of Facility and Laboratory Management, Guangxi University for Nationalities, Nanning, China

\begin{abstract}
City spirit is a spirit and total moral character with a certain historical development stage of one social community which lives in a certain area. There must be moral rationality and ethical implications in it. Based on the ethical analysis and ethical direction of city spirit. Summarizes the ethical value of city spirit: that is integrate multiple interest expression. And then put forward the way to the ethical construction of the city spirit.
\end{abstract}

KEYWORD: City spirit; ethical cerebration

\section{INTRODUCTION}

"City spirit" refers to the spiritual character and mental outlook in certain historical stages, entirely presented by the members of the society living in certain regions, includes the history and culture, architectural style, configuration and pattern of the city, as well as the comprehensive quality, the degree of civilization and the value orientation of the citizens, it is embodyed by the material construction, management style and running state of the city [1]. The text surveys city spirit from the perspective of ethics, by means of analysing the ethical foundation, ethical orientation and the ethical value of city spirit it would further consider the ethical construction of city spirit.

\section{THE PREMISE OF ANALYSING: CITY IS AN ETHIC ENTITY}

City is considered as an organism geographical entity which can systemly constitute and spatially aggregate all kinds of cultural factors because of human settlement, the communication relationship between people is correspondingly engendered in the process, and certain ethical relationship is naturally engendered from this communication relationship. Marx once said: "Human nature, in its reality is the sum of all social relations." [2] In this respect, the city essence is the expansion of human nature, it embodys as the community of human relationship and as the meaningful synthesis which is jointly created and lived by social man. Hagel had advocated the ethics investigation method Starting from the view of substantive, in his view, passing a series of development link from family to civil society and country, ethic entity ultimately becomes entity of ethic spirit, in this sense, ethic entity can be explained as "ethical entity whose core is social relations system of necessity and universality" [3]. Starting from no other than this, distinguish city from the general sense of the geographical concept, namely underline that urban residents live as a social community which agglomerates moral emotion, value pursuit in common, maintain and share value and benefit, jointly fulfil moral commitments. Society 's development eventually maintain on the basis of overall harmonious, it demands the social multi-interest body to form a social atmosphere which is able to meet the needs of most people and to promote social overall development and good moral relationship by social identifying and value compromising.

Therefore, ethic entity essencely refers to social community which make up unique ethical paradigm, it bocomes the key explaining the ethical implication of city spirit that clarifying the ethical relation and regulations which are contained in the ethic entity called city, the ethical foundation and ethical orientation of the construction of city spirit.

\section{THE ETHICAL FOUNDATION: CITY MEMBER MUTUALLY BENEFIT AND COEXIST}

Distinguished from the traditional homogenous ethical relationship which produced by the members of the rural in virtue of factors such as the blood 
relationship, geopolitical relationship, the common cultural background and religious belief, in virtue of high population density, strong liquidity, social division of labor and strong professionalization in ciyies, the ethical relationship of urban society embody as the heterogeneity which have two aspects of value significance: for one thing, as relatively independent benefit main body of equal rights and freedom right, the social members' existing mode and life style are the social bonds of universality and diversity based on exchanging, and they reach the universal identifying sense to rule of conduct of each other in their concept and practice action, for another, basing on the heterogenic city of urban society, the interior of social members certainly arise all kinds of complicated social relationships and conflict of interest, no other than which make human society to affirm the necessity and "general in nature" besides to show the brutal view such as "the survival of the fittest" and "select the superior and eliminate the inferior "in the natural metabolism. As Engels said: "People consciously or unconsciously, in the final analysis is always from the actual relationship which their class status base on -- from their economic relations in the course of production and exchange, get their ethical concept." [4]

In other words, as all creatures in nature must live and develop by energy, material and information exchanging, the course of city system evolution also is the course of heterogenic city increasing, if so, it would promote increasingly to form complex feedback network, system material flow and information flow in social members.[5]It is the diversified urban ecological environment which break the unitary of the self-sufficient mode of production, and the monopoly of unidirectional material, energy and information in the traditional farming culture, it brings up diversified living space, provide possibility with equally and fully using materia and energy of system to everyone, make the relationship of every benefit main body to be most widely adjusted in the course of producing and living, a variety of basic economic and social order are effectively maintained, thus symbiotic relation in social members come into being.

\section{THE ETHICAL ORIENTATION: CONSTRUCT HARMONIOUS CITY PROPERTY}

"harmony" attributes to the basic value judgement "ought to be", is an expression of "kindness" which is aimed at satisfying social subjects with the object property "ought to" .In which, harmonious means friendly, pulling together for a common cause, gets the meaning amiable and unisonous, underlines trying hard to avoid conflicting and contradicting. meanwhile underlines achieving harmony and uniformity of diversity by means of balancing and
blending.[6]Since human society existed, "harmony" has been ethics idea and standard of conduct of the Chinese nation which is of universal significance, and has been beautiful ideal human society always diligently strive after, it always should have been the ethical aim and moral dimension indispensible in the course of constructing city spirit.

In modern society, the main function of city spirit is to rationally critique the real life of the city with the way "ought to be" in virtue of rational consciousness, and is to provide rational reference and value goal for regulating and controlling the social order, promoting urban construction, the development of social economy and culture and integrated development of urban inhabitants, "it embodies how people arrange for their lives and how people compose their inherent order of life".[7]The constructing take mutually benefit and coexist as the ethical foundation, and to some extent this relationship unify with the value goal city spirit seek for, as harmony is on the premise of the balance and mutual benefit of rights and interests among communicative subjects, that is achieve mutualism in the process of exchanging between right and duty separately by means of restricting the right and duty of subjects. If a city can't construct the social atmosphere of interest balance, fairness and justice, honest and trustworthy and kindheartedness and kindness, the communication of urban inhabitants is in status of the high cost and high risk, in that way, the society would be in the status of disharmony, In contrast, when the cities are in good social atmosphere of "All for one and one for all", urban inhabitants take achieving "harmonious coexistence" as the ethical aim of their own, in that way, the constructing of city spirit not only obtains ethical value therefrom, but feasiblely ensure the benefit request of urban inhabitants.

\section{THE ETHICAL VALUE: INTEGRATE MULTIPLE INTEREST EXPRESSION}

City spirit is a deep-seated social consciousness, and is the reflection "is so" of the social being in the spiritual realm such as economic, political, and cultural life of city, meanwhile, as the summation of city cultural characteristics, it would in the in-depth level influence and change world outlook and values of people living in the city, and directly determines the status of moral system "ought to be" which the city take on.

City is a society of highly differentiation and multi-structure whose principal character is differentiation and diversity of social structure and stratum produced by the diversity of interest subjects, it also means that if there are not effective coordination and integration to the individual behavior which is of respective behavioral motive, 
special needs and interest pursuit, the society would be disorderly and out of control. The significance of generating of city spirit rests with providing possibility which is able to make social members live in harmony and share the profits, and impelling umbilical cord contact of profit among the seemingly fragmented social members, no other than such a umbilical cord contact makes the interest expression of social members embody macroscopic integrity and consistency, ultimately form spiritual resultant which is able to promote social development.[8]

at present our country is in the social transition period, the development of society is achieved in the process of the game playing among various stakeholders, as a moral community which converges multiple stakeholders, the basic prerequisite of the existence and development of city exactly is achieving the unification composed by the specificity kindness of multiple stakeholders and the universal social kindness. The ethical connotation of city spirit isn't a ideology express and serve a certain class interests but the consensus moral of different classes and strata, or rather, a integrated morality, it aims to make an overall recognition and Macro regulation to the interest of various interest subjects in the city, to guide the development direction and speed and to imperceptibly form citizens' value judgments and supporting belief.

\section{THE ETHICAL CONSTRUCTION: EXALT FROM "VALUE CONSENSUS" TO "TOGETHER ACTION"}

From moral perspective, the content exalt from "value consensus" to "together action" contains two dimensions of society and the individuality: one is the unity of theory and practice in the social public field, the other is the unity of individual moral cognition and moral practice, but we often dissevers the relationship between "consensus" and "action" in the construction of inherent ideology which contains city spirit. The reason is the essence isn't the topdown propaganda and education to urban inhabitants but the value rationality identity from the bottom up which forms owing to the self-examination to " ought to be", of which the content concerning realm of spirit and norm of morality like city spirit. Therefore, the government should establish ethics safe idea and system by means of system, mechanism and culture atmosphere, especially set up interpersonal sense of ethical security of individuals and nations, individuality and collectivity, individuality and others. Ethics safety and sense of ethical security are important factors which affect the coherence of city spirit and the quality of life and happiness of urban inhabitants. A society lacking of ethics safety, also is a high-risk society in which everyone feels insecure, the deep reason of interpersonal tensions, human indifference, the mentality of Hating the rich of the minority and the relevant malignant event in present-day society is the deficiency of sense of public ethical security. By contrast," Kin Concealment System" in the eyes of Saints, "kind fathers and filial sons" and "show love and respect as good brothers should" In traditional Chinese society in a sense exactly is the way of ethics safety in society and family, but these conceptions have almost been used up by the ethical conflict brought by the market mechanism, social mobility and multi-parties of interest in modern society.

The most important isn't forming "value consensus" but exalting to "together action" to constructing city spirit, and the philosophy "carry out by actual efforts" not only depends on individual to "Start from me", but also demands nation and society trying hard to practice, and changing the bygone "moral education" and "spirit indoctrination" into "moral training", setting up a variety of ways of environment and approach to "moral training", establishing corresponding encouraging system of moral reward and punishment in order to impel people to get into the habit of good behavior custom and social conduct to be formed.

\section{ACKNOWLEDGEMENT}

This research was financially supported by the Ideological and Political Education Theory and Practice Project of Guangxi Universities No.2012LSZ043.and by the Humane Social Research Project of Guangxi Universities No.SK13YB135.

\section{REFERENCES}

[1] Zonghao Bao. On the Urban Spiritual Culture. Academic Monthly, 2006(1).

[2] The complete works of Marx Engels: volume 1. Beijing: People's Publishing House, 1956:56.

[3] (Germany) Hagel. Principle of law philosophy. Yang Fan, Qitai Zhang, translate. Beijing: the Commercial Press, 1982:165.

[4] The selected works of Marx Engels: volume 3. Beijing: People's Publishing House, 1995:434.

[5] Jingwei Wu, Pingmei Gao. Human development of civil society: the moral culture and political ecology of Chinese civil society. Shanghai: Shanghai Sanlian Bookstore, 2012:45.

[6] Shiguo Wang. Four Aspects for Building Socialist Harmonious Society. Journal of Gannan Teachers College 2005(1).

[7] Hao Fan. The historical construction of Chinese ethical spirit. Taipei: literary history and philosophy publishing house, 1995:28.

[8] $\mathrm{Pu}$ Dong. The urban culture construction research in a harmonious society. Dong Bei: Northeast Forestry University, 2010. 